\title{
An overview of technology and research in electrode design and manufacturing in sinking electrical discharge machining
}

\author{
Bhola Jha ${ }^{1, *}$, K.Ram $^{1}$ and Mohan Rao ${ }^{2}$ \\ ${ }^{I}$ Dep. of Industrial and Production Engineering, Dr B. R. Ambedkar National Institute Of Technology, Jalandhar-144011, Punjab,India \\ ${ }^{2}$ Dep. of Mechanical Engineering \& Mining Machinery Engineering, Indian School of Mines (ISM), Dhanbad-826004, Jharkhand, India
}

Received 29 September 2010; Revised 14 December 2010; Accepted 25 January 2011

\begin{abstract}
Electrical discharge machining $(\mathrm{EDM})$ is one of the earliest non-traditional machining processes, based on thermoelectric energy between the workpiece and an electrode. In this process, the material is removed electro thermally by a series of successive discrete discharges between two electrically conductive objects, i.e., the electrode and the workpiece. The performance of the process, to a large extent, depends on the material, design and manufacturing method of the electrodes. Electrode design and method of its manufacturing also affect on the cost of electrode. Researchers have explored a number of ways to improve electrode design and devised various ways of manufacturing. The paper reports a review on the research relating to EDM electrode design and its manufacturing for improving and optimizing performance measures and reducing time and cost of manufacturing. The final part of the paper discusses these developments and outlines the trends for future research work.
\end{abstract}

Keywords: EDM, Process parameters, MRR, Electrode design, Manufacturing

\section{Introduction}

Electrical discharge machining is basically a nonconventional material removal process. This process is widely used to produce dies, punches and moulds, finishing parts for aerospace and automotive industry and surgical components [1]. This process can be successfully employed to machine electrically conductive workpieces irrespective of their hardness, shape and toughness [2-4]. During EDM process, the electrode shape is mirrored in the workpiece. The electrode dimensions are determined in such a way that spark gap between the surface to be generated and electrode is maintained as shown in Figure 1. Higher gap is required for higher removal rate but also higher gap results in poor surface quality. The performance of the EDM process is highly dependent on the material and the design of the electrodes. The electrode has two parts, i.e. electrode tool and holder. Both these parts are often designed and manufactured into single piece. The simple electrodes are normally manufactured by conventional cutting methods, but machining, casting, electroforming or metal spraying may produce complicated shape electrodes. In die-sinking electrical discharge machining process, in general, either fixed electrodes are used to produce die cavities or a rotary device works in conjunction with a $\mathrm{CNC}$ to control the electrode's path in various EDM profiling [5-7]. Manufacturing method of electrode also affects manufacturing time, cost and performance of EDM electrode.

*E-mail address: kojha.gve@gmail.com

ISSN: 1791-2377 @ 2011 Kavala Institute of Technology. All rights reserved.

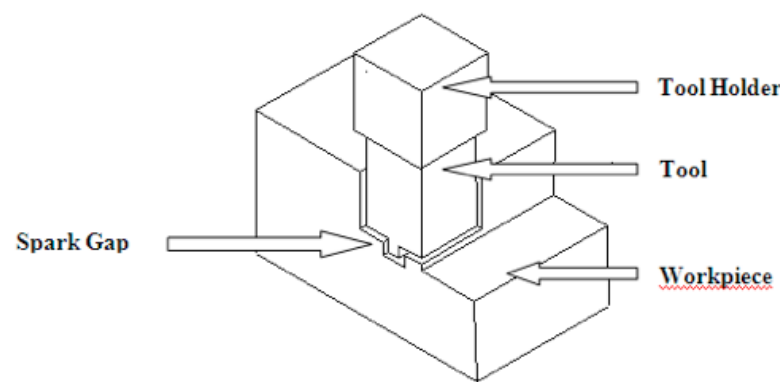

Fig. 1. Electrode and the workpiece

In present day's scenario, EDM is used as a standard technique for manufacturing production tooling out of hardened materials for production of dies and moulds. Due to rapid tool wear involved; many electrodes are often required for machining each cavity. Tool wear affects machining accuracy and demand for frequent tool replacement adding to around 50\% of tooling cost. Alternatively use of rapid tooling technique minimizes the electrode development lead-time and reduces the tooling cost considerably. Therefore, design, development and manufacturing of EDM electrode play a very vital role in EDM technology. A lot of published EDM research work relates to parameter optimization for a particular work tool interface or to determine best tool material for a particular work material. Many innovative electrode material and designs have also been tried. The objective of this review paper is to report and review the research work carried out by researchers in the field of EDM electrode design and manufacturing. 


\section{Different aspects of electrode design}

\subsection{Principles of electrode design}

The prime role of EDM tool is to convey the electrical pulse to allow erosion of workpiece with little or no tool wear. Considerable effort has gone into the EDM tooling problem regarding inexpensive tool materials, ease of manufacture, rapid workpiece erosion, coupled with low tool erosion etc $[8,9]$. To improve machining efficiency, roughing, finishing and semi-finishing electrodes are used in EDM process. EDM is mostly employed in obtaining mould cavities, cylindrical hole machining and 3-dimensional cavity machining. In cylindrical hole machining, through holes and cavities are produced by electrodes of constant cross section. However, in 3-dimensional cavity machining any cavity is machined with one or more electrodes with varying cross section. The tool design procedure is approximately same for both the cases [10]. Ding et al. [11] have discussed basic principles of electrode design. Poluyanov [12] have classified EDM tools into three groups depending upon the value of area of projection of electrode on the workpiece plane. The workpiece plane is considered perpendicular to direction of tool feed. A systematic diagram for these three types of tool is shown in Figure 2. Two major factors governing the tool design are material selection and electrode wear.

\subsubsection{Material selection for EDM electrode}

The selection of the most appropriate electrode material is a key decision in the process plan for any sinking EDM job. The important variables to be considered for selection of electrode material are material removal rate, tool wear rate, surface roughness, machinability and material cost. Properties of different electrode materials and their influence on EDM performance as well as on fabrication of electrodes have been summarized in EDM handbooks [13, 14, 15]. Electrode material should have the basic properties like electrical and thermal conductivity, a high melting temperature, low wear rate, and resistance to deformation during machining.

Since electric current is "cutting tool", in EDM, higher conductivity (or conversely, lower resistivity) promotes more efficient cutting. Drozda [16] explained that the tool electrode is responsible to transport the electrical current to the workpiece. Therefore, any material to be used as a tool electrode is required to conduct electricity. Since EDM is a thermal process, it would be logical to assume that the higher the melting point of the material of electrode, the better the wear ratio will be between electrode and workpiece. Even though EDM is often thought of as a "zero force" process, every individual spark is a very violent process on a microscopic scale, exerting considerable stress on the electrode material. How well the material responds to these hundreds and thousands of these "attacks" on its surface will be a significant factor in determining the electrode material's performance regarding wear, surface finish, and ability to withstand poor flushing conditions. The mechanical properties of electrode materials most often considered for electrode materials are:

- Tensile strength

- Transverse Rupture Strength

- Grain Size

- Hardness
These mechanical properties affect the ease in fabrication of the electrode [15]. According to the theory the mechanical properties of the workpiece and the tool electrode have negligible influence on machining performance. However, the thermo physical properties of the workpiece and electrode (thermal and electrical conductivity, thermal expansion, heat to vaporize from room temperate, melting and boiling temperature) have considerable influence on the process performance in terms of material removal rate, electrode wear and surface integrity of the workpiece [17].

The above mentioned desirable properties may provide general guidelines for electrode material selection but due to highly stochastic nature of EDM process, the basis for selection of particular work-tool interface is empirical rather than theoretical. Empirical results regarding performance of different work- tool interface is summarized in Table 1[10].

Electrode materials fall into two main categories: metallic and graphite. Today, metallic electrodes are only used in perhaps $10 \%$ of sinking EDM applications (with the exception of small hole drilling). The primary advantage of metallic electrode materials is their electrical conductivity and mechanical integrity. Mechanical integrity is especially important in both sharp corner and poor flushing conditions. The primary disadvantages of metallic electrodes are difficulty in fabrication and low cutting speeds. Graphite is a preferred electrode material for $90 \%$ of all sinking EDM applications.

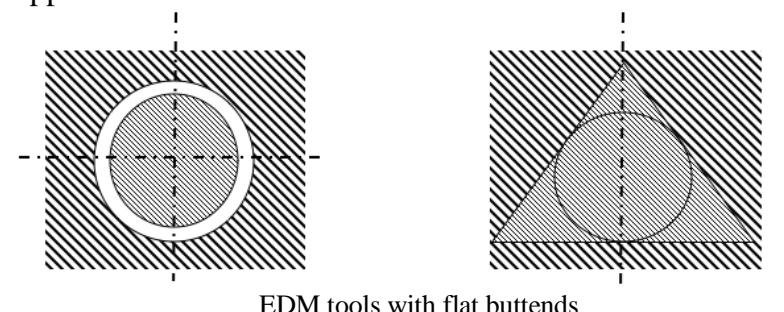

EDM tools with flat buttends
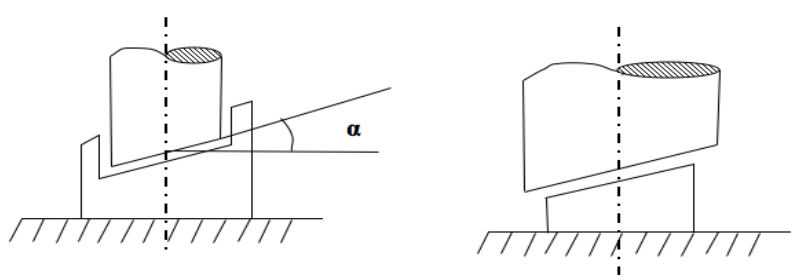

EDM tools with flat buttends and with different inclinations

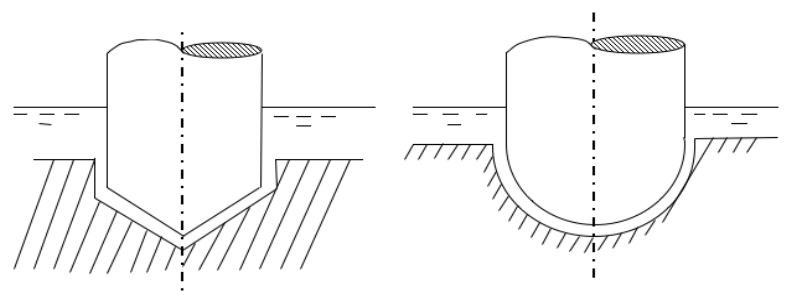

EDM tools with flat buttends and with 3-D shapes

Fig. 2. Classification of EDM electrode [12]

Therefore, it is important that we expend considerable effort to understand electrodes have a greater rate of metal removal in relation to its wear [18]. Graphite does not melt in the spark gap; rather, at approximately $6062{ }^{\circ} \mathrm{F}(3350$ ${ }^{\circ} \mathrm{C}$ ), it changes from a solid to a gas. Because of graphite's relatively high resistance to heat in the properties and application. Studies reveal that graphite spark gap (as compared to copper), for most jobs it is a more efficient 
electrode material. Graphite has certain properties quite different than metal based electrode materials:

- Graphite has an extremely high melting point. Actually, graphite does not melt at all, but sublimes directly from a solid to a gas at a temperature thousands of degrees higher than the melting point of copper. This resistance to temperature makes graphite an ideal EDM electrode material.

- Graphite has significantly lower mechanical strength properties than metallic electrode materials. It is not as hard, strong, or stiff like metallic electrode materials. However, since the EDM process is one of relatively low macro mechanical forces, these property differences are not often significant.

- Due to the significant differences between metallic electrodes and graphite, there are certain properties, unique to graphite. These properties are-

Particle Size: Generally, the smaller the particle size, the better the mechanical properties of the graphite, resulting in finer detail, better wear, and better workpiece surface finish.

Density: Since graphite is a porous material, its density must be closely controlled. Generally, higher density is preferable.

Flexural Strength: Flexural strength is a measure of the strength. Generally, graphite with the smallest particle size has the highest flexural strength.

Hardness: Hardness is generally a function of the particle size, porosity, and binder material. Hardness can be very important to the success of machining and grinding operations. Graphite is widely used due to its significant production advantages over metallic electrode materials.

Speed: Graphite is faster than copper in both roughing and finishing, usually by a factor of 2:1.

Machinability: Graphite machines and grinds an order of magnitude faster than copper, and can also have more detail easily machined into it. Graphite doesn't have to be deburred like any metallic does, further reducing electrode fabrication costs.

In fact, there is a vast range of materials used for manufacturing electrodes like brass, tungsten carbides, electrolytic copper, copper-tungsten alloys, silver-tungsten alloy, tellurium-copper alloys, copper-graphite alloys, graphite etc. The five commonly used electrodes are: copper, brass, tungsten, zinc, and graphite. In addition, some electrode materials are combined with other metals in order to cut more efficiently. Tungsten has a melting point similar to graphite, but tungsten is highly difficult to machine. Metallic electrodes usually work best for machining materials which have low melting points as aluminum, copper, and brass. As for steel and its alloys, graphite is preferred. The general rule is: metallic electrodes should be applied for low temperature alloys and graphite electrodes should be applied for high temperature alloys. However, exceptions also exist. For example, despite higher melting points for cobalt, tungsten, and molybdenum, metallic electrodes like copper are recommended due to the higher frequencies needed to EDM these materials. During unsupervised CNC cutting, the copper electrode can be sized automatically by using a sizing plate. The copper electrode can then be reused for a finishing cut or used to produce another part. Vartanian \& Rosenholm [19] have pointed out that for many years there have been discussions about the relative merits of the different EDM electrode materials. The major debates are about copper versus graphite. The EDM users in different parts of the world have been using different electrode materials for doing exactly the same jobs. Normally, copper is mainly used in Europe or Asia for historical reasons. Graphite is the chosen material by the majority of EDM users from the USA. Most EDM jobs that can be done with copper can also be executed with graphite. The end result might be the same, but the cost to accomplish the job can be vastly different. In practical terms the choice of the electrode material will depend mainly on the tool size, the workpiece requirements, type of EDM machine and methods of making the electrodes. Other important factors shall be considered when selecting the electrode material:

- Workpiece material removal rate $\left[\mathrm{mm}^{3} / \mathrm{min}\right]$ : A correct choice of EDM parameters to the pair tool /workpiece electrode materials will increase its value.

- Electrode resistance to wear: The volumetric and corner wears in electrode are very important in finish EDM operations of fine details. Minimization of those wears requires choosing proper parameters and electrode material.

- Workpiece surface roughness: Good workpiece surface quality is obtained by the proper choice of electrode material, good flushing conditions and adequate EDM parameter settings.

- Tool electrode material machinability: Copper and graphite are the most commonly used. However, it is important to select an electrode material where the macro and micro geometry can be easily machined. It promotes the reduction of machining time and costs.

- Electrode material cost: On average, fine graphite is about three times more expensive than copper. The choice shall be done considering the company facilities (e.g, machinetools, CAD/CAM software technology etc). It also includes the know-how on machining copper and graphite electrodes, the complexity of the electrode and its difficulty to be redressed and the knowledge on EDM parameters.

\subsubsection{Electrode wear in EDM}

The tool wear process is quite similar to the material removal mechanism as the tool and workpiece are considered as a set of electrodes in EDM [1]. EDM electrode wear may be categorized into four types- (a) Volumetric (b) Corner (c) End and (d) Side [10]. Corner wear directly influence shape of the cavity. Heaviest electrode wear occurs at the corners. Jeswani [20] have analyzed the electrode erosion by dimensional analysis. An empirical relation was developed relating the material eroded from tool electrode to the energy pulse, density, thermal conductivity, specific heat and latent heat of vaporization of electrode material. Crookall et al. [21] have explained the effect of debris concentration on erosion rate. They have reported that increased debris resulted in increased erosion. Also use of distilled water as dielectric results in lower erosion rates in comparison to kerosene as dielectric. Mohri et al. [22] have investigated the tool wear mechanism and claimed that tool wear is affected by the precipitation of carbon from the hydrocarbon dielectric on the electrode surface during 
sparking. They also reported that the rapid wear on the electrode edge was due to the failure of carbon to precipitate at difficult-to-reach regions of the electrode tool. Dauw [23] has developed a geometrical simulation of EDM describing the development of electrode wear and part geometry. It was also considered as an off-line process planning technique as the simulation algorithm is largely based on MRR, TWR and spark gap. However, the simulation of discharge location and spark gap, which are dependent on the distribution of debris concentration, was reported by Kunieda and Kiyohara [24] yielding a more realistic representation of the sparking phenomenon. Kunieda et al. [25] have introduced a reverse simulation of EDM obtaining the shape of the electrode based on the desired workpiece shape. Marafona and Wykes [26] have introduced a wear inhibitor carbon layer on the EDM electrode surface by adjusting the settings of the process parameters prior to normal EDM conditions. Although, the thickness of the layer have made a significant improvement on the tool wear rate but it had little effect on the MRR. Saha [27] has investigated the erosion rates of few work- tool interfaces with similar as well as dissimilar metals. It was found that the distribution of energy per pulse between the electrodes, dielectric and plasma and hence their erosion rates depends on electrode material pair and their polarity.

Minimization and compensation of electrode wear has always been one of the major motives in electrode design process. Researchers have proposed several methods for compensating electrode wear in EDM. Orbiting of the electrode relative to the workpiece is the most common machining strategy proposed by researchers for compensating the tool wear. It involves the electrode tool making a planetary motion producing an effective flushing action, thus improving part accuracy and process efficiency [28].

\subsection{Relation of electrode design with EDM performance measures}

Majority of researchers use material removal rate (MRR), tool wear rate (TWR) and surface roughness (SR) as performance indices. Electrode design affects the spark gap between EDM electrodes. Spark gap differs for different electrode geometries and also for different surface finish condition required. Higher spark gap results in higher voltage setting and improved flushing conditions resulting in higher MRR and rough surface.

Flushing condition may also be improved by suitable electrode design. MRR is highly affected by types of dielectric and method of flushing [29]. Flushing is useful to remove debris from discharge zone even if it is difficult to avoid concentration gradient and inaccuracy $[30,31]$. Better flushing conditions result in both increases in material removal rate and tool wear. Better flushing conditions is reported by introducing electrode rotation, tube electrode design and electrode with eccentric hole [6, 32-34]. Electrode design also depends upon method of flushing employed. Figure 3 shows electrode designs for three basic types of flushing methods. Wang and Yan [35] have reported the effect of flushing methods on performance measures for $\mathrm{Al}_{2} \mathrm{O}_{3} / 6061 \mathrm{Al} \mathrm{MMC}$ and rotating electrode. They found that with side flushing, both the MRR and TWR is considerably less than with injection and suction flushing. Surface roughness value was found to be approximately the same for each type of flushing method.

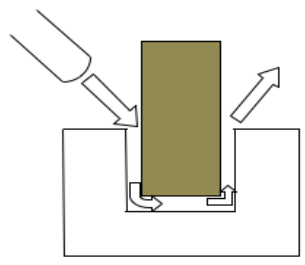

Side Flushing

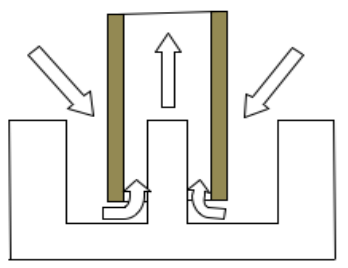

Electrode Suction Flushing

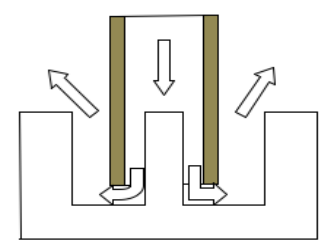

Electrode Injection Flushing
Fig. 3. Electrodes shapes for basic types of flushing methods.

Mohan et al. [34] have investigated the effect of tube electrode hole diameter on the performance measures. They found that electrode tube hole diameter significantly affects the MRR, TWR and SR. The decrease in hole diameter has produced a better MRR, SR and higher TWR.

\subsection{Different 3-D form tool designs}

Generally 3-D form tools are employed in EDM process which are found costly, take more time for their manufacturing and associated with high wear rate particularly when subjected to cutting of complex shapes [1, $36,37]$. Research on 3D solid form tool with different geometries revealed that best tool shape for higher MRR and lower TWR is circular in shape, followed by triangular, rectangular, and square cross sections [38]. Yan and Wang [35] compared the performance of solid electrode and tube electrode. They observed that both the MRR and TWR considerably increase for tube type electrode in comparison to solid type electrodes. The same researchers compared the performance of a stationary electrode, a rotational electrode, and a rotational electrode with an eccentric through-hole in terms of machining characteristics [32]. Higher MRR and TWR were reported for rotational electrode with an eccentric through-hole. This was possibly attributable to the superior debris disposal effect.

3D tools when applied for complex shapes together with high penetration depths was found to introduce flushing difficulties. This in turn restricts the removal of debris causing abnormal discharge so that only $60 \%$ useful machining time is obtained [39]. Flushing conditions may be improved by increasing the electrode gap but it results in lower metal removal rates [40]. Bayramoglu and Duffill [41] investigated the machining characteristics of $3 \mathrm{D}$ form and cylindrical tools. They reported that CNC EDM machine have the capability for developing $3 \mathrm{D}$ shapes using part programs to generate servo-controlled tool movements on four axises. CNC EDM can facilitate more sophisticated tool motions and the ability to generate complex shapes with simply shaped electrodes. With CNC EDM machines the machining can now take place in the $\mathrm{X}, \mathrm{Y}, \mathrm{Z}$ and rotational $\mathrm{C}$ directions. However these advanced CNC capabilities were not fully utilized by toolmakers [42]. Instead of using multi-axis CNC capabilities, the design and manufacturing of 3D shaped workpieces was largely dependent on plunging of formed tool along z-axis direction. 
Table 1. Performance of work-tool interface in EDM [10]

$\mathrm{C}_{\mathrm{WR}}$ : Corner wear ratio

\begin{tabular}{|c|c|c|c|c|c|c|c|c|c|c|c|}
\hline \multirow{2}{*}{$\begin{array}{l}\text { Sr. } \\
\text { No. }\end{array}$} & \multirow{2}{*}{$\begin{array}{l}\text { Material } \\
\text { of } \\
\text { Electrode }\end{array}$} & \multirow{2}{*}{$\begin{array}{l}\text { Workpiece } \\
\text { Material }\end{array}$} & \multirow{2}{*}{$\begin{array}{l}\text { Available } \\
\text { form }\end{array}$} & \multicolumn{2}{|c|}{ Performance } & \multirow{2}{*}{$\begin{array}{l}\text { Type of } \\
\text { machining }\end{array}$} & \multicolumn{2}{|c|}{ Wear ratio } & \multirow[t]{2}{*}{ Machinability } & \multirow{2}{*}{$\begin{array}{l}\text { Best } \\
\text { application }\end{array}$} & \multirow{2}{*}{$\begin{array}{l}\text { Limitations } \\
\text { and } \\
\text { undesirable } \\
\text { uses }\end{array}$} \\
\hline & & & & $\begin{array}{l}\text { Relaxation } \\
\text { Type }\end{array}$ & $\begin{array}{l}\text { Pulse } \\
\text { type }\end{array}$ & & $\begin{array}{l}\mathbf{V}_{\mathrm{WR}} \\
\mathbf{R}\end{array}$ & $\begin{array}{l}\mathbf{C}_{\mathrm{WR}} \\
\mathbf{R}\end{array}$ & & & \\
\hline 1 & Graphite & Steels & $\begin{array}{l}\text { Blocks, } \\
\text { Rods }\end{array}$ & Poor & Excellent & $\mathrm{R}, \mathrm{F}$ & 100:1 & $5: 1$ & Excellent & $\begin{array}{l}\text { Press } \\
\text { tooling dies }\end{array}$ & Carbide \\
\hline 2 & Brass & All metals & $\begin{array}{l}\text { Brass } \\
\text { tube, } \\
\text { Wire }\end{array}$ & Fair & Excellent & $\mathrm{R}, \mathrm{F}$ & $1: 1$ & $7: 1$ & Good & Hole size & Deep slots \\
\hline 3 & $\begin{array}{l}\text { Copper- } \\
\text { tungsten }\end{array}$ & All metals & $\begin{array}{l}\text { Short } \\
\text { Bars, } \\
\text { Flats, } \\
\text { Shims, } \\
\text { Wire, } \\
\text { Tubes }\end{array}$ & Excellent & Excellent & S-F, F & $8: 1$ & $3: 1$ & Fair & $\begin{array}{l}\text { Machining } \\
\text { of carbides, } \\
\text { slots and } \\
\text { micro } \\
\text { machining }\end{array}$ & Large areas \\
\hline 4 & Copper & All metals & $\begin{array}{l}\text { Bars, } \\
\text { Wire, } \\
\text { Tube }\end{array}$ & Excellent & Good & $\mathrm{R}, \mathrm{F}$ & $2: 1$ & $1: 1$ & Good & Hole & $\begin{array}{l}\text { Deep slots } \\
\text { with close } \\
\text { tolerance }\end{array}$ \\
\hline 5 & Tungsten & $\begin{array}{l}\text { All metals } \\
\text { and } \\
\text { refractory } \\
\text { metals }\end{array}$ & $\begin{array}{l}\text { Wire, } \\
\text { Rods }\end{array}$ & Good & Good & S-F, F & $10: 1$ & $5: 1$ & Poor & $\begin{array}{l}\text { Small } \\
\text { slots\& } \\
\text { holes }\end{array}$ & $\begin{array}{l}\text { Irregular } \\
\text { holes }\end{array}$ \\
\hline 6 & $\begin{array}{l}\text { Tungsten } \\
\text { Carbide }\end{array}$ & $\begin{array}{l}\text { All metals } \\
\text { and } \\
\text { refractory } \\
\text { metals }\end{array}$ & $\begin{array}{l}\text { Sintered } \\
\text { Rods }\end{array}$ & Good & Good & S-F, F & $10: 1$ & $6: 1$ & Poor & $\begin{array}{l}\text { Small } \\
\text { slots\& } \\
\text { holes }\end{array}$ & $\begin{array}{l}\text { Irregular } \\
\text { holes }\end{array}$ \\
\hline 7 & Steel & $\begin{array}{l}\text { Non } \\
\text { ferrous } \\
\text { materials }\end{array}$ & $\begin{array}{l}\text { Rods, } \\
\text { Ingots, } \\
\text { Forgings }\end{array}$ & Poor & Good & S-F & $4: 1$ & $4: 1$ & Good & $\begin{array}{l}\text { Through } \\
\text { holes }\end{array}$ & Carbide \\
\hline 8 & Zinc & Steel only & $\begin{array}{l}\text { Cast } \\
\text { Shapes }\end{array}$ & Poor & Fair & $\mathrm{R}, \mathrm{S}-\mathrm{F}$ & 2 & $7: 1$ & Good & $\begin{array}{l}\text { Forging } \\
\text { Die cavities }\end{array}$ & $\begin{array}{l}\text { Through } \\
\text { holes }\end{array}$ \\
\hline 9 & Aluminum & Steel only & $\begin{array}{l}\text { Cast } \\
\text { Shapes, } \\
\text { Extruded } \\
\text { bars }\end{array}$ & Poor & Fair & $\mathrm{R}$ & $5: 1$ & $5: 1$ & Good & $\begin{array}{l}\text { Forging } \\
\text { cavities }\end{array}$ & $\begin{array}{l}\text { Through } \\
\text { holes }\end{array}$ \\
\hline
\end{tabular}

Notes: R: Rough machining

F: Finish Machining

S-F: Semi-Finish Machining

$\mathrm{V}_{\mathrm{WR}}$ : Volume wear ratio 


\subsection{Plate, frame and ball ended cylindrical tool design}

Four types of tooling methods have been reported by researchers for producing $3 \mathrm{D}$ shape cavities in workpiece as shown in Figure 4 [41- 43].

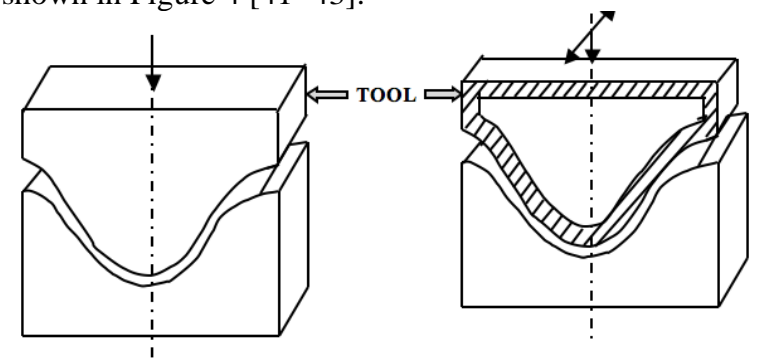

3D FORM TOOL

FRAME TOOL
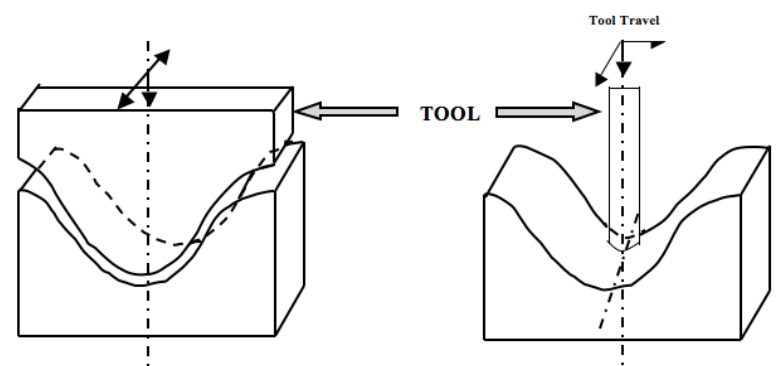

PLATE TYPE TOOL

BALL ENDED CYLINDRICAL TOOL

Fig. 4. Design difference between 3D form tool, frame tool, plate type tool and ball ended cylindrical type tool.

Plate type tools can only be applied with basic shapes (spheres, conics and simple 2D sweeps) and intermediate shapes (complex 2D sweeps, ruled surfaces and fillets). When applied for complex shaped deep cavities, plate tools results in poor dielectric flow causing the debris to accumulate and be suspended in the gap. With simple plate tooling, however, good flushing conditions can be achieved even in the most difficult circumstances [44]. The application of plate type tools results in high MRR, high relative electrode wear, good dimensional accuracy and better surface finish.

Application of frame type tool in EDM is a novel technique for generation of linear, circular and curved contours without using any complex shaped electrodes. Bayramoglu and Duffill [43] have discussed the brief advantages of using frame type tools. Compared to form type tools, frame type tools are easy to produce and inexpensive. With application of frame type tool, the machining time reduces considerably. In EDM process surface finish depends upon generator setting and tool surface area [45]. Smaller machining surface results in better surface finish. The total machining area of frame type tool is smaller than for $3 \mathrm{D}$ form tool. Therefore application of frame type tool results in better surface finish. Also, catering for dimensional changes in frame type tools could be carried out under NC control rather than employing different tools for roughing, semi finishing and finishing operations as in case of 3D form tool. Therefore, frame type tools are less expansive. Like plate type tools, frame type tools are only suitable for basic shapes (spheres, conics and simple 2D sweeps) and intermediate shapes (complex 2D sweeps, ruled surfaces and fillets). Yu et al. [46] have presented a new method, called uniform wear method, for 3D micro-EDM. Simple electrodes such as with round or rectangular section were applied. Uniform wear at the end of the electrode was realized by layer-by-layer machining. This maintained the original electrode shape and converted the three dimensional electrode wear to a linear one. By compensating the linear electrode wear, complicated three dimensional cavities were successfully machined. This technique was developed for micromolds, but the applicability for normal size molds was also confirmed.

Like 3D form tools, ball ended cylindrical tools can be employed for producing basic (spheres, conics and simple 2D sweeps) and intermediate (complex 2D sweeps, ruled surfaces and fillets) sculptured (CAD obtainable shapes, higher order polynomials) and general (3D implied shapes indicated on drawings). Standard cylinder or ball ended cylinder as the tool electrode is employed in contour or CNC EDM milling technology [47, 48]. Ding and Jiang [47] have studied special requirements on tool paths demanded by contour EDM machining and have proposed a two-phase tool path generation method for 4-axis contour EDM rough milling with a cylindrical electrode. In the first phase of the method, initial tool paths for virtual 3 -axis milling were generated in a commercial CAD/CAM systemUnigraphics, which provides users with plenty of options in choosing suitable tool path patterns. From these tool paths, cutter contact points between electrode and workpiece are reversely calculated. In the second phase, considering the special requirements of EDM, which include discharging gap compensation, electrode wear compensation, DC arcing prevention, etc., the electrode was adjusted to an optimized interference-free orientation by rotating it around the cutter contact points obtained in the previous phase. This new orientation together with the reference point of electrode is output as new tool path. The whole algorithm has been integrated into unigraphics, machining simulations and tests have been conducted for 4-axis contour EDM rough machining. Being a special application of conventional $\mathrm{EDM}$, contour or CNC EDM machining of free-form surfaces is a new technology emerged in recent years. Due to its special machining properties, although the electrode moves in the same way as a cutter in mechanical milling, tool paths generated for milling cannot be used directly in contour EDM machining. Discharge gap compensation, electrode wear compensation and many other factors have to be considered in the tool path generation process. Chang and Hong [48] have investigated a buffered digital differential analyzer algorithm in a computerized numerical controller performs milling electric discharge machining of a curve constructed from a sequence of segments using a traditional computer-aided manufacturing system. The proposed algorithm interpolates more than one segment in a sampling interval and supports the effective machining of a parametric curve when the electrode crosses the connection between the short segments. The accuracy of the speed and the trajectory of motion were ensured without the time function of the parameter specified by two terms of a Taylor expansion, such as in a real-time parametric curve interpolator. The proposed algorithm is compared with the reference-word interpolation and real-time polynomial interpolation used in a milling EDM to confirm improvements of erosion speed. After the parametric curve has been converted into the segments using a fixed parameter increment under constrained chord error and the memory size, the buffered digital differential analyzer algorithm interpolates more than one segment using a simple digital differential analyzer in the main program during an interruption interval. The algorithm selects appropriate commands in interrupt service routine after the results obtained by the digital differential 
analyzer have been pushed into the memory, to ensure that the computation time of the interrupt service routine is short. The algorithm guarantees the accuracy of the line-connected contour and the speed without using real-time polynomial interpolation. The actual chord error can be maintained below the threshold as required, and the actual speed is similar to that determined from two terms in the Taylor expansion. The rates of erosion of the milling EDM with a high sampling rate and a high speed along short segments exceed those of traditional reference-word interpolation and real-time polynomial interpolation. Standard cylinder or ball ended cylinder as the tool electrode may be applied in EDM without making the male electrode necessary to yield a part of desired shape [48-50]. Bayramoglu and Duffill [41] have investigated the effects of tool path, pick feed and electrode rotation for flat and ball ended cylindrical electrodes. Many methods of determining the electrode wear rate and a system that included mechanisms of automatic measurements and compensation of electrode deformation for such tools have been reported in literature [49, 51-54]. Halkaci et al. [55] have proposed a new practical method for dimensional measurements of semi-spherical parts for the standard tool electrodes used in electrical discharge machining. In this proposed method, numerous coordinate data representing sphericity of ball surface are obtained spending less time and lower cost. The ball ended cylindrical tool used for experimentation is shown in Figure 5 [55].

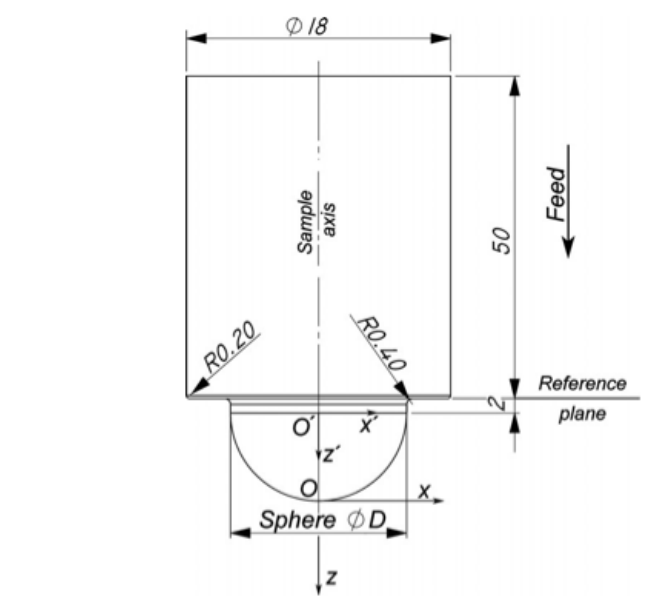

Fig. 5. Typical ball ended cylindrical tool [55]

The deviation from spherical form due to electrode wears during machining and consequent difficult tool path generations are disadvantages of ball ended cylindrical tools.

\subsection{Tool design for multi-spark and multi-electrode EDM}

Kunieda and Muto [56] proposed the multi-spark EDM method which was newly developed to obtain higher removal rates and lower energy consumption compared with conventional EDM. This technique is a modification of the basic EDM principle because in basic EDM, only single discharge is delivered for each electrical pulse. To set up multiple discharge points for each pulse two types of electrode design has been proposed by researchers. Mohri et al. [57] divided a tool electrode into multiple electrically insulated electrodes connected to the pulse generator through a resistor. In this case, after a discharge occurs in the gap between one of the divided electrodes and the workpiece, the gap voltages at other electrodes are maintained at the open circuit voltage level for a certain period of time until the surface electric charge over these electrodes is redistributed or another discharge occurs. Therefore, finally discharge can occur at different electrodes simultaneously. Suzuki et al. [58] and Kubota et al. [59] proposed a twin electrode discharge system for the electric discharge dressing of metal bonded grinding wheels. Connecting the pulse generator to one of the two twin electrodes, the grinding wheel, and the other twin electrode serially formed the discharge circuit. In this system, for each pulse, two discharge points can be obtained simultaneously at both the gaps between the twin electrodes and the grinding wheel using only one pulse generator. Kunieda and Muto [56] used twin electrode discharge system as shown in Figure 6 . The removal rate and energy efficiency were found higher than those of conventional EDM in which there is only one discharge point for each pulse.

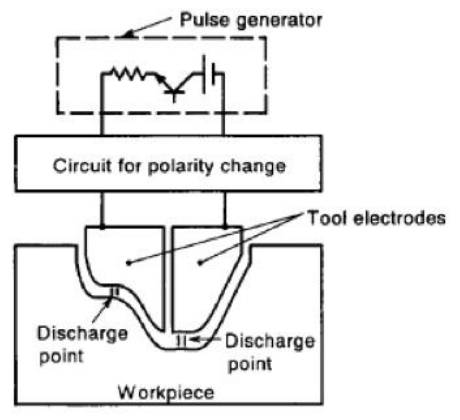

Fig. 6. Principle of Multi-spark EDM [56]

Chen et al. [60] devised a new mechanism of cutting pipe combined with electrical discharge machining. This new mechanism was designed with multi electrode system controlled by planet gear system in die sinking EDM as shown in Figure 7. The newly developed mechanism resulted in both increase in material removal rate and relative electrode wear ratio for SUS 304 workpiece material. Influence of process parameters have been investigated on MRR for developed mechanism. The largest removal rate and the lowest electrode wear ratio were reported when workpieces rotate at $8 \mathrm{rpm}$.

\subsection{Computer assisted EDM electrode design}

Ding et al. [11] have introduced a computer-aided EDM electrode design system for die and mould manufacturing. Under this system, when electrode boundaries are selected, the electrode tool, tool holder and a work coordinate system are created automatically. Thus, by this system, electrode tools and its holders can be created automatically from workpiece design. This design system also generates a workpiece co-ordinate system for machining purpose. The system has been tested and proved to be able to shorten electrode design lead time significantly. The proposed method begins with the detection of the uncut region in the mould insert that requires machining. The boundary of the region is then obtained and projected onto the plane that is perpendicular to the EDM direction (X-Y Plane). The trimming and extension of the boundary curves are invoked when necessary for ensuring that the projected boundary forms a close loop. After that, the close-loop boundary is extruded along the $\mathrm{Z}$ direction to create a solid that contains the region that requires the EDM process. Subtraction of the 
part geometry from the extruded solid gives the solid model of the electrode. Although the electrode created by Ding's method has the correct shape to perform the EDM process for the uncut region in the part, the electrode may itself contain uncut regions. In such cases, the single electrode has to be split into multiple electrodes to avoid machinability problem of the single electrode. This process is tedious and requires an experienced engineer to ensure proper splitting.

Mahajan et al. [61] proposed the basic principles of designing knowledge-based system for automated EDM electrode design. This system works by taking into account, the logic that an experienced EDM specialist would use to design electrodes. First the overall methodology to design EDM electrodes automatically is described on the highest level then the details of this methodology are explained followed by conclusions. The success of this system depends to some extent to the radius detection software algorithm. General methodology proposed in the research work is shown in Figure 8. However, these rules are presented using high-level description, and automating the electrode design process with them would be a difficult task, which has not been addressed in this research work.

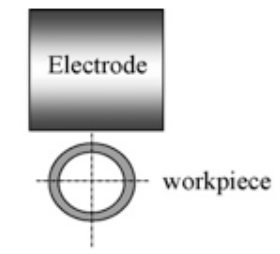

Conventional E.D.M

(Single electrode)

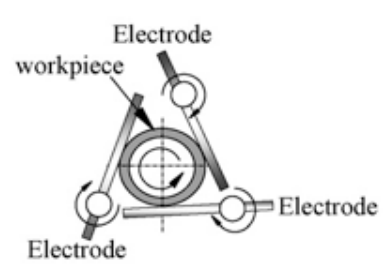

Fast Cutting Mechanism of Pipes by E.D.M

(Multiple electrode)
Fig. 7. Difference between conventional and multi electrode EDM [60]

Lee and $\mathrm{Li}$ [62] have developed an intelligent CAD tool that supports EDM electrode design. This CAD tool uses a new technique that recursively splits the EDM region into sub-regions until machinable electrodes can be constructed. This proposed intelligent CAD tool has been implemented in and integrated with a commercial CAD/CAM system. This tool has been tested with 40 different real designs to demonstrate its capability in handling a wide variety of geometric shapes. Design engineers have been invited to evaluate its performance. Performance data revealed that at least a $50 \%$ improvement in the efficiency of the design process can be achieved with the current implementation.

\section{Different aspects of electrode manufacturing}

Electrical discharge machining is used extensively in the machining of dies and moulds with hardened material. Generally, the cost and time consumption in the die and mould machining by EDM is the manufacturing of electrodes, which can account for over $50 \%$ of the total machining cost [63]. The cost of manufacturing electrodes is generally determined by the complexity of the geometry and the accuracy demanded. The electrodes for electricaldischarge machining are generally fabricated using conventional machining methods. Uniformly dimensioned electrodes are cheaper to produce. For complex threedimensional shapes, machining, casting, electro-forming or metal spraying may produce electrodes. Fabrication of electrodes using rapid prototyping (RP) technology can also reduce the cost of producing electrodes with complex geometry. Research and development work in EDM electrode manufacturing is reported in following subsections.

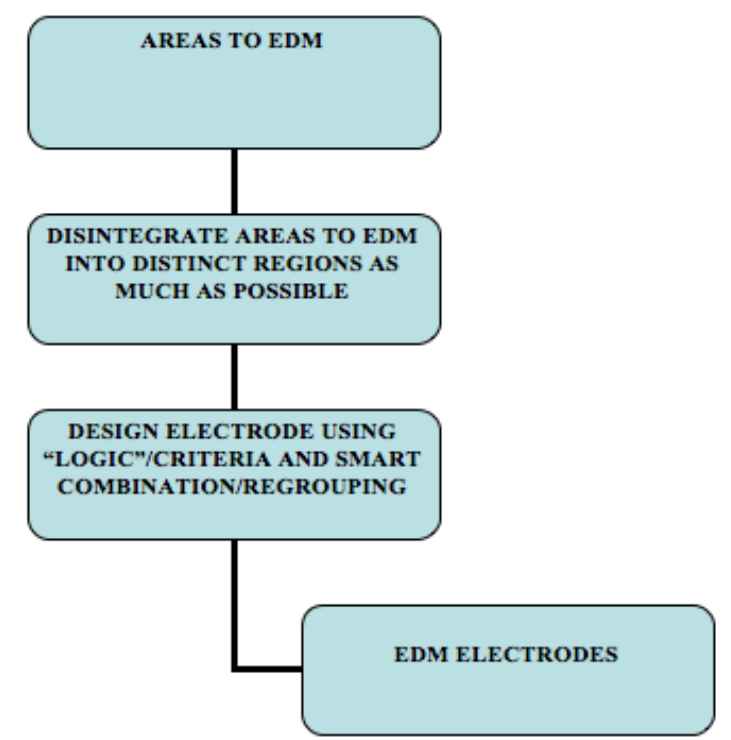

Fig. 8. General idea of the method to design electrodes automatically [61]

\subsection{Electrode manufacturing using casting and machining}

These are conventional techniques of EDM electrode manufacturing. Casting is used for $\mathrm{Zn}$ based die casting alloy, Al alloys and $\mathrm{Zn}-\mathrm{Sn}$ alloys [64]. Electrode are often die cast by standard Zn-base die casting alloys, Zn- Sn (8020 to 50-50) alloys and aluminum alloys. These electrodes may be re-melted for reuse [10]. However, cast electrodes have various defects like blowholes, mismatching and micro cracks. Electrodes of copper and its alloys can be machined by using conventional machines [65]. In United States, high speed machining of graphite has become an increasingly popular solution. Application of these conventional techniques is limited due to complex cavities.

\subsection{Electrode manufacturing using powder Metallurgy (PM)}

Earlier, the majority of EDM work was being done by using mechanically formed tool electrodes. The present EDM user is compelled to search for alternative tooling such as powder metallurgy (PM) method of electrode fabrication which is more economical and faster to manufacture. A complex electrode manufactured by conventional method may cost around 100 times more than a simple square electrode. Therefore, conventional method is suitable for less complex shaped electrodes or for complex shaped electrode in few numbers. However in the powder metallurgy, a large number of EDM tool electrodes can be manufactured from a single die and punch assembly. This results in an overall reduction of EDM tooling cost for mass production of EDM 
electrodes. Therefore, powder metallurgy turns out to be a viable alternative to produce tool electrode in which the desirable properties of different materials can be combined. Moreover, the thermal, electrical, mechanical and micro structural properties like density and pore shape of PM electrodes can be effectively controlled by the process variables such as compacting pressure and sintering temperature. An example is an alloy of $\mathrm{Cu}-\mathrm{W}$ made through PM where tungsten particles are uniformly embedded in highly conductive copper matrix. The electrodes made by using powder metallurgy technology from special powders have been used to modify EDM surfaces in recent years, to improve wear and corrosion resistance.

Samuel and Philip [66] have carried out theoretical and experimental study into the effect of PM electrode on various aspects of EDM. They have established that such electrodes are technologically practicable and by varying compaction and sintering variables, EDM related properties can be controlled. Zaw et al. [67] have investigated compounds of $\mathrm{ZrB}_{2}$ and $\mathrm{T}_{\mathrm{i}} \mathrm{S}_{\mathrm{i}}$ with copper at various composition of EDM electrode. Either solid-state sintering or liquid phase sintering manufactured these electrodes. Performance of newly sintered material is compared with conventional electrode materials such as copper, Coppertungsten and RT produced from selective laser sintering.

Beri et al. [68] have investigated the usefulness of electrodes made through powder metallurgy in comparison with conventional copper electrode during electric discharge machining. It was found that $\mathrm{Cu}-\mathrm{W}$ electrode (made through $\mathrm{PM})$ gives high surface finish where as the $\mathrm{Cu}$ electrode is better for higher material removal rate.

In spite of sintering constraint, PM manufactured electrodes have proved to be best alternative method of electrode manufacturing due to ease of production and control of properties.

\subsection{Electrode manufacturing using rapid prototyping and rapid tooling}

Rapid prototyping is a motivating innovative additive technology for quickly creating physical models and functional prototypes directly from CAD models. Rapid tooling, is generally, related with fast tooling production using prototypes made by rapid prototyping. Technologists involved in rapid tooling processes development are now devoting much of their efforts in reducing lead-times and development costs. Rapid prototyping (RP) technology offers great advantages like improved quality, shortening time to market, and reduction in the cost of fabrication of complex shaped EDM electrodes [67, 69].

Between 1991 and 1996, several attempts were made to develop applications and techniques for rapid prototyping EDM tooling [70-76]. Arthur and Dickens [72] have investigated manufacturing parameters and discovered that when the copper plating layer on the electrode prototype is above $175 \mu \mathrm{m}$ thick than it can help in preventing the electrode prototype from breaking during EDM. Arthur et al. [77] have investigated wear and fracture mechanism of stereolithography SL-EDM electrodes. Such electrodes present wear and failure mechanisms that are detrimental. Arthur et al. [74] used RP parts as electrodes for EDM. They have found a direct generation route with rapid prototype parts as EDM electrodes. Thin-coated stereo lithography models were successfully used in machining hardened tool steel up to a depth of $4 \mathrm{~mm}$. The photo-polymer electrode was coated by silver nearly $10 \mu \mathrm{m}$ thick onto the surface and then electroformed of copper with thickness of $180 \mu$ m.It was claimed that these electrodes are suitable for finishing cut in EDM die-sinking. Stucker et al. [78] have attempted to apply a composite of $\mathrm{ZnB}_{2} / \mathrm{Cu}$ mixed with an adhesive to prepare a rapid prototyping model by selective laser sintering (SLS), and then to make an EDM electrode after the removal of the adhesive by heating. Zaw et al. [67] compared the performance of different EDM electrodes made by conventional methods, PM route and rapid prototyping. Yarlagadda et al. [79] have discussed the use of rapid prototype patterns made by the stereo lithography technique for the manufacture of EDM electrodes. The use of other techniques such as silicone rubber casting and electroforming in the making of the EDM electrode has also been described. Their research work deals with the viability of using an electroformed shell of copper, backed with a suitable material, as an EDM electrode and it was concluded that electroformed copper electrodes possess an excellent potential for use. Noguchi and Nakagawa [80] have developed a new powder casting process suitable for making metallic rapid tools by powder sintering. Allan et al. [81] have applied electroforming combined with different RP technologies for the production of complex EDM electrodes with fairly reasonable time scale. In their study, the electrode life, wear of electrodes, and eroded cavity depth against wall thickness has been discussed. It was found that application of filled thin-walled electroforms as EDM electrodes is possible. Zhao et al. [82] have manufactured an electrical discharge machining metal prototype directly using the selective laser sintering (SLS) process. It was found that the wear rate of the electrode approaches to that of a general electrode, and the surface roughness of the cavity is acceptable at the same machining conditions. The preferable surface finish of a cavity can be acquired using roughening or semi-finish machining parameters with this kind of electrode. Dimla et al. [83] have described a collaborative research program aimed at investigating the use of quick EDM electrodes obtained via appropriate rapid prototyping techniques in finishing laser-sintered tools. Two methods were employed in obtaining the EDM electrodes: copper coating of stereo lithography models and copper coating of direct metal laser sintered (bronze) models. The amount of copper deposited on both electrodes models was proved problematic as the electroplating process was unable to deposit enough copper in the inner cavities of the electrodes. Consequently, the electrodes were not found suitable for the envisaged EDM process. Ferreira et al. [84] have investigated the application of indirect rapid tooling (RT) technology to manufacture EDM copper electrodes from investment casting, with wax prototypes made by Thermo Jet $3 \mathrm{D}$ printing, a rapid prototyping (RP) technique. The reverse engineering (RE) method was utilized to transform the point cloud data of an object surface, obtained from 3D digitizing, in a 3D CAD surface model dataset. Based on a case study, some functional conclusions were made for the application of RT in manufacturing EDM electrodes aided by $3 \mathrm{D}$ digitizing and $\mathrm{RE}$, validating the accomplishment by the integration of these technologies and methodologies in EDM manufacturing processes. Kechagias et al. [85] have reviewed the published research work on RT electrodes. They tabulated the results of the performance of such electrodes. Hsu et al. [86] have investigated an effective method for manufacturing electrical discharge machining electrodes using the rapid prototyping system based on electroless plating (nickel plating) and electroforming 
(copper). This method was shown to finish the development of die-sinking electrical discharge machining electrodes, shorten the electrode manufacturing process, and decrease the manufacturing duration as well as the cost of electrodes. Test results indicated that no crack was found on the electrode and promising electrical discharge machining effects.

Although many variations of RT electrodes were developed and extensive research was performed, until now the results of RT electrode performance have shown that they do not meet the desirable standards for use as an alternative to conventional $\mathrm{CNC}$ or high speed machining (HSM) milling electrodes [85].

\subsection{Electrode manufacturing using some other techniques}

Researchers have also tried some innovative techniques for fabrication of EDM electrode. Tsai et al. [87] have proposed a new method of blending the copper powders contained resin with chromium powders to form tool electrodes. Such electrodes are created at low pressure $(20 \mathrm{MPa})$ and temperature $\left(200^{\circ} \mathrm{C}\right)$ in a hot mounting machine. The results showed that using such electrodes have facilitated the formation of a modified surface layer on the workpiece after EDM, with remarkable corrosion resistant properties. Kadir Dursun and Can Cogun [88] have investigated the performance of electrodes formed by using copper wire bunches $\left(\mathrm{WBE}_{\mathrm{s}}\right)$. WBEs are proved to be economical as compared to conventional solid electrode. The use of WBE electrode for rough machining decreases machining cost and time. It decreases both the number of electrodes required and delay in starting machining due to preparation of electrode. Shibayama and Kunieda [89] have described improvement of machining characteristics of EDM of deep slots using a tool electrode which has micro holes for jetting dielectric liquid over the working surface. The electrode was made by the diffusion bonding of two copper plates, over an interface on which micro grooves for jetting the dielectric fluid were formed using electrolyte jet machining. Use of the newly developed tool electrode was found to shorten the processing time and improve machining accuracy significantly compared with the conventional solid electrode. Since the holes are micro in size, the outlet shapes are not replicated onto the bottom surface of the slot machined.

\section{Remarks and future trends}

The objective of the review article has been aimed to report the work carried out by various researchers in the field of EDM electrode design and manufacturing, and to bridge the gap between the untouched areas. After an elaborate scrutiny of the published work, the following remarks emerge from the existing published work.

- Most of the published work on EDM tool design relates to parametric optimization, improving performance measures and selection of suitable work-tool interface. There is not much published work on EDM electrode design.

- In addition, published works in tool design include a few materials like copper and its alloys, graphite etc. Use of new materials like cermets which has low tool wear rate, high corrosion resistance and reasonably good conductivity has not been sufficiently investigated.

- Generally, tool makers use thumb rule or trial and error method for EDM tool design. Therefore, scientific investigation of design of circular as well as non circular electrodes is identified as an important area of research. Results of investigations may be extended for fabrication of tools with complex cavities.

- Like material removal mechanism, electrode wear mechanism (ERM) is also a complex phenomenon. Simplified assumptions and approaches in theoretical modeling, have led to large disagreement with results. Therefore, there is no sound theoretical basis for selecting a suitable tool material and design for a work material. Selection of suitable work-tool interface is mainly based on empirical results.

- Most of research work in EDM relates to use of 3D form tool. Alternate types of tools like frame type and plate type are yet to be tried for work-tool interfaces.

- Application of plate, frame and ball ended cylindrical tool design seems to have a lot of potential for commercial applications. Their applications depend upon exploitation of CNC EMD capabilities allowing servo controlled tool movement along four axes. However, market survey shows that these capabilities are not fully being exploited by toolmakers. The reason for the same needs to be explored and thoroughly investigated.

- $\quad$ Even in 3D form tools, not much published work is available corresponding to use of different tool cross-sectional geometries like rectangular, triangular etc. on performance measure like MRR, EWR etc. Therefore, effect of different tool geometries on MRR, EWR, surface roughness etc. has to be explored for more work materials.

- In case of non circular electrode design, effects of profile parameters of a particular profile (like inscribed angle in case of triangular electrode) on performance measures of EDM process are yet to be investigated sufficiently.

- Hollow tube and eccentric drilled holes type electrodes are reported to have a positive impact on MRR due to improved flushing conditions. Such designs need investigations for more work materials to evaluate their case to case effects.

- Multi spark EDM and multi electrode EDM are relatively new techniques for MRR improvement and are still under experimental stage. More empirical validation using different workpiece materials is required before the method is recommended for commercial applications.

- Although EDM electrodes formed by powder metallurgy route is a recommended alternative method for electrode manufacturing due to ease of production and control of properties but there is limited published work on investigating performance of such electrodes. Most of the published work relates to electrode formed by conventional techniques probably because of their easy availability. PM electrodes should be 
investigated thoroughly for many work-tool interfaces.

- Although extensive research work has been performed on variations of rapid tooling electrodes but still they do not meet desirable standards for use as an alternative to conventional $\mathrm{CNC}$ or high speed machining electrodes. This is due to evident disadvantages like poor surface roughness and dimensional inaccuracy. Future research work may be directed for minimizing such disadvantages for making RP electrode as a feasible alternative.

- There is negligible published work available on comparative study of various electrode designs and electrodes manufactured by different techniques with same/different work materials. So, there is a lot of scope for future research work in this field.

- Researchers have investigated innovative ways of EDM electrode manufacturing using diffusion bonding, wire bunch electrodes, electrodes with micro holes etc. However, there is limited published literature regarding performance of such electrodes. Such electrodes should be investigated thoroughly for many possible work materialelectrode material combinations before their commercial application.

\section{Summary}

Design and manufacturing of electrode play an important role in EDM technology. The present review paper reports research and development work carried out by various researchers in the same field. After elaborate scrutiny of the published work, future direction for the EDM research have been indicated as a novel contribution to the archival literature.

\section{List of abbreviations}

$\begin{array}{ll}\text { EDM: } & \text { Electrical Discharge Machining } \\ \text { MRR: } & \text { Material Removal Rate } \\ \text { CNC: } & \text { Computed Numerically Controlled } \\ \text { CAD/CAM: } & \text { Computer Aided Design/ Computer } \\ \text { Aided Manufacturing } \\ \text { TWR: } & \text { Tool Wear Rate } \\ \text { SR: } & \text { Surface Roughness } \\ \text { PM: } & \text { Powder Metallurgy } \\ \text { RP: } & \text { Rapid Prototyping } \\ \text { RT: } & \text { Rapid Tooling }\end{array}$

\section{References}

1. Ho KH, Newman ST (2003) State of the art electrical discharge machining (EDM). Int J Mach Tools Manuf 43: 1287-1300.

2. Kansal HK, Singh S, Kumar P (2007) Technology and research developments in powder mixed electric discharge machining (PMEDM). J Mater Process Technol 184:32-41.

3. Abu Zeid OA (1997) On the effect of electro-discharge machining parameters on the fatigue life of AISI D6 tool steel. J Mater Process Technol 68 (1): 27-32.

4. Ramasawmy H, Blunt L (2004) Effect of EDM process parameters on 3D surface topography. J Mater Process Technol 148:155-164.

5. Yan BH, Wang CC, Liu WD, Huang FY (2000) Machining characteristics of $\mathrm{Al} 2 \mathrm{O} 3 / 6061 \mathrm{Al}$ composite using rotary EDM with a disk like electrode. Int J Adv Manuf Technol 16(5): 322-333.

6. Soni JS, Chakraverti G. (1994) Machining characteristics of titanium with rotary electro-discharge Machining. Wear 171: 5158.

7. Don, K.S. (1994) Electro discharge machining. Fu-Wen publish Co, $\mathrm{p} 40$.

8. Gough PJC (1985) Electrode manufacturing: Conventional and new techniques. Proceedings of the First Electrical Machinery Symposium (EM85), Birmingham, UK :64-81.

9. Carter, GA, Jergas I (1983) Choice of electrical discharge machining tooling. E.C. Jameson (Ed.), Methods and Applications, Society of Manufacturing Engineers, Dearborn, MI, 1983: 57-61.

10. HMT (1991) Production Technology. Tata McGraw Hill.

11. Ding XM, Fuh JYH, Lee KS (2002) Computer aided EDM electrode design. Computers and Industrial Engineering 42: 259269.

12. Poluyanov VS (1995) On effects of electrode-tool shape on optimum electrical conditions of EDM roughing of cavities and holes. Proceedings of International Symposium for electro machining (ISEM-11), Lausanne, Switzerland: 191-200.

13. Machining Data Handbook (1980) 3rd Edition, Vol. 2, Machinability Data Center, Ohio, Section 11, 10.

14. Guide to Material Engineering Data and Information (1986) ASM International metals Park, Ohio.

15. Roger Kern (2008) Sinker electrode material selection. EDM Today, July/August 2008 Issue

16. Drozda T J (1998) Tool and Manufacturing Engineers Handbook: Machining, USA: Society of Mechanical Engineers, Vol.5.

17. Amorim FL, Weingaertner WL (2007) The behavior of graphite and copper electrodes on the finish die-Sinking electrical discharge machining (EDM) of AISI P20 tool Steel. J. of the Braz. Soc. of Mech. Sci. \& Eng 29, 4: 366-371
18. Complete EDM Handbook, http://www.reliableedm.com/Complete\%20EDM\%20Handbook/Co mplete\%20EDM\%20Handbook_11.pdf

19. Vartanian, M.A. and Rosenholm, O., 1992, "Methods of manufacturing" Manufacturing conference, Chicago, USA. Vol. 1, pp 1-16.

20. Jeswani ML (1979) Dimensional analysis of tool wear in electrical discharge machining. Wear, 55: 153-161.

21. Crookall JR (1985) Basic factors in EDM operators with shaped electrodes. International Journal of machine tool design research: 491-498.

22. Mohri N, Suzuki M, Furuya M, Saito N (1995) Electrode wear process in electrical discharge machining. Ann. CIRP 44 (1):165168.

23. Dauw D (1998) Geometrical simulation of the EDM die-sinking process. Ann. CIRP 37 (1): 191- 196.

24. Kunieda M, Kiyohara M (1998) Simulation of die-sinking EDM by discharge location searching algorithm. Int. J. Electr. Machining 3:79-85.

25. Kunieda M, Kowaguchi W, Takita T (1999) Reverse simulation of die-sinking EDM. Ann. CIRP 48 (1):115-118.

26. Marafona J, Wykes C (2000) A new method of optimizing material removal rate using EDM with copper-tungsten electrodes. Int. J. Mach. Tools Manuf. 40 (2):153-164.

27. Saha R, Kumar R, Mohan Muju (2000) Influence of electrode materials and polarities on the electrode erosion rates in EDM. Society of manufacturing engineers. <http://www.sme.org/cgibin/get-item.pl?MR00-208\&2\&SME\&>

28. Snoeys R, Staelens F, Dekeyser W (1986) Current trends in nonconventional machining techniques. Ann. CIRP 35 (2):467-480.

29. Wong YS, Lim LC, Lee LC (1995) Effect of flushing on electrodischarge machined surfaces. J Mater Process Technol 48:299-305.

30. De Bruyn HE (1970) Some aspects of the influence of gap flushing on the accuracy in finishing by spark erosion. Ann. CIRP 18: 147151.

31. Masuzawa T, Cui X, Taniguchi N (1992) Improved jet flushing for EDM. Ann. CIRP 41/1: 239-242.

32. Wang CC, Yan BH (2000) Blind-hole drilling of Al2O3/6061Al composite using rotary electro-discharge machining. J Mater Process Technol, 102: 90-102.

33. Mohan B, Rajadurai A, Satyanarayan KG (2002) Effect of SiC and rotation of electrode on electric discharge machining of $\mathrm{Al}-\mathrm{SiC}$ composite. J Mater Process Technol124: 297-304. 
34. Mohan B, Rajadurai A, Satyanarayana KG (2004) Electric discharge machining of $\mathrm{Al}-\mathrm{SiC}$ metal matrix composites using rotary tube electrode. J Mater Process Technol 153-154: 978-985.

35. Yan BH, Wang CC (1999) The machining characteristics of Al2O3/6061 Al composite using rotary electro-discharge machining with a tube electrode. J Mater Process Technol 95: 222-231.

36. Weller EJ (1984) Nontraditional Machining Processes. Society of Manufacturing Engineers: 61

37. BP Manual (1986) Dielectric fluid for electro discharge machining.

38. Sohani MS, Gaitonde VN, Siddeswarappa B, Deshpande AS (2009) Investigations into the effect of tool shapes with size factor consideration in sink electrical discharge machining (EDM) process. Int J Adv Manuf Technol 45: 1131-1145.

39. Smith GV (1975) The level of development in EDM. IEE Conf. Electrical Meth. Mach. Form. 133 : 101.

40. Singh UP (1984) The influence of EDM parameters. Proceedings of the 25th MTDR Conference: 337

41. Bayramoglu M., Duffill AW (1994) Systematic investigation on the use of cylindrical tools for the production of 3D complex shapes on CNC EDM machines. Int J Mach Tools Manuf 34(3): 327-339.

42. Bayramoglu M, Duffill AW (1995) Manufacturing linear and circular contours using CNC EDM and frame type tools. Int J Mach Tools Manuf 35 (8): 1125-1136.

43. Bayramoglu M, Duffill AW (1992) Production of three dimensional shapes using computational electrical discharge machining. Proc.Int. M.T.D.R. conf.: 107-112.

44. Bayramoglu M, Duffill AW (2004) CNC EDM of linear and circular contours using plate tools. J Mater Process Technol 148:196-203.

45. De Bruyn, HE, Pekelharing AJ, Delft TH (1980) Comparison of various erosion systems with rectangular and trapezoidal pulse forms', CIRP Annals - Manufacturing Technology 29(1): 103-106.

46. Yu ZY, Masuzawa T, Fujino M (1998) Micro-EDM for threedimensional cavities-development of uniform wear method. Annals of the CIRP 47 (1): 169-172.

47. Ding S, Jiang R (2004) Tool path generation for 4-axis contour EDM rough machining. Int J Mach Tools Manuf 44:1493-1502.

48. Chang YF, Hong, RC (2005) Parametric curve machining of a CNC milling EDM. Int J Mach Tools Manuf, 45 (7-8): 941-948.

49. Mizugaki Y (1996) Contouring electrical discharge machining with on measuring and dressing of a cylindrical graphite electrode. Journal of Precision Engineering 20: $1514-1517$.

50. Bleys P, Kruth JP, Lauwers, B. (2004) Sensing and compensation of tool wear in milling EDM. J Mater Process Technol 149:139146.

51. Kaneko T, Tsuchiya M (1987) Contouring electric discharge machining by three-dimensional numerical control using cylindrical electrode. J. Jap. Soc. Precision Engineering 53(4): 71-76.

52. Kaneko T, Tsuchiya M (1988) Three-dimensional numerically controlled contouring by electrical discharge machining with compensation for the deformation of cylindrical tool electrodes. Precision Engineering 10(3): 157-163.

53. Kaneko T, Tsuchiya M, Kazama A (1992) Improvement of 3D NC contouring EDM using cylindrical electrodes-optical measurement of electrode deformation and machining of free-curves (2nd Report). in: Proceedings of International Symposium on ElectricMachining (ISEMX) EDM C/BC: 364- 367.

54. Konno H, Sato M, Kishinami T, Saito K (1989) Contouring electric discharge machining using pipe electrode. Jap. Soc. Precision Engineering (9): 1603-1608.

55. Halkaci HS, Mavi O, Yigit O (2007) Evaluation of form error at semi-spherical tools by use of image processing. Measurement 40 : 860-867.

56. Kunieda M, Muto H (2000) Development of multi-spark EDM. Ann. CIRP 49 (1): 119-122.

57. Mohri N, Saito N, Takawashi T, Kobayashi K (1985) Mirror-like finishing by EDM. Proc. of the 25th MTDR Conf.:329-336.

58. Suzuki K, Mohri N, Uematsu T, Nakagawa T (1985) ED truing method with twin electrodes. Preprint of Autumn Meeting of JSPE: 575-578.

59. Kubota M, Tamura Y, Okita T (1989) Electrocontact discharge dressing of metal bonded diamond grinding wheels using twin electrode system. Proc. of ISEM 9, 1989: 22-25.

60. Chen SL, Lin MH, Hsieh SF, Chiou SY (2008) The characteristics of cutting pipe mechanism with multi-electrodes in EDM. Journal of materials processing technology 203:461-464.

61. Mahajan KR, Knoppers GE, Oosterling, JAJ, Van Luttervelt, CA (2004) Knowledge based design of EDM electrodes for mould cavities pre-machined by high-speed milling. J Mater Process Technol149:71-76.

62. Lee $\mathrm{YH}, \mathrm{Li} \mathrm{CL}$ (2009) Automation in the design of EDM electrodes. Computer-Aided Design 41: 600-613.

63. Li L, Wong YS, Fuh JYH, Lu L (2001) EDM performance of TiC/ copper-based sintered electrodes. Materials \& Design 22:669-678.

64. Ghosh A, Mallik AK, (1985) Manufacturing Science. East West Press Private Limited.

65. Machinery Hand Book (2000) 26th Edition, Industrial Press Inc 200, Madison Avenue, New York-10016- 4078.

66. Samuel MP, Philip PK (1997) Power metallurgy tool electrodes for electrical discharge machining. Int J Mach Tools Manuf 37 (11):1625-1633.

67. Zaw HM, Fuh JYH, Nee AYC, Lu, L. (1999) Formation of a new EDM electrode material using sintering techniques. J Mater Process Technol 89-90: 182-186.

68. Beri N, Maheshwari, S, Sharma C, Kumar A (2008) Performance evaluation of powder metallurgy electrode in electrical discharge machining of AISI D2 steel using taguchi method. International Journal of Mechanical, Industrial and Aerospace Engineering, 2:3 2008.

69. Campbell RI, Bernie, MRN (1996) Creating a database of rapid prototyping system capabilities. J. Mater Process Technol 61: 163167.

70. Dickens PM, Smith PJ (1992) Stereolithography tooling. Proceedings of the 1st European Conference on Rapid Prototyping and Manufacturing, Nottingham, UK, 6-7 July 1992: 309-317.

71. Jensen KL, Hovtun R (1992) Making electrodes for EDM with rapid prototyping. In: Proceedings of the 3rd International Conference on Rapid Prototyping, Dayton, Ohio USA, 7-10 June 1992:295-301.

72. Arthur A, Dickens, PM (1995) Rapid prototyping of EDM electrodes by stereolithography. In: Proceedings of the International Symposium for Electromachining (ISEM XI), 17-20 April 1995, Lausanne, Switzerland: 691-699.

73. Arthur A, Cobb RC, Dickens PM (1995) The potential for rapid prototyped EDM electrodes using stereolithography models. Proceedings of the 1st National Conference on Rapid Prototyping and Tooling Research, , 6-7 November 1995, Buckinghamshire College, Great Missenden, UK: 221-235.

74. Arthur A, Dickens PM, Cobb RC (1996) Using rapid prototyping to produce electrical discharge machining electrodes. Rapid Prototyping J 2(1): 4-12.

75. Arthur A, Dickens PM (1996) Material removal and tool wear rates in EDM with stereolithography electrodes. Proceedings of the 5th European Conference on Rapid Prototyping and Manufacturing, 46 June 1996, Helsinki, Finland:157-169.

76. Arthur A, Cobb RC, Dickens PM (1996) Combining electroforming and electroplating to produce EDM electrodes from rapid prototype models. In: Proceedings of the 12th National Conference on Manufacturing Research, 9-12 September1996, Bath, UK: 341345 .

77. Arthur A, Dickens PM, Bocking C, Cobb RC (1996) Wear and failure mechanisms for SL EDM electrodes. In: Proceedings of the 7th Solid Freeform Fabrication Symposium, 12-14 August 1996, Austin, Texas: 175-189.

78. Stucker BE, Bradley WL, Norasettekul S, Eubank PT (1996) The production of electrical discharge machining electrodes using SLS preliminary results. Solid Freeform Fabr Symp.: 278- 286.

79. Yarlagadda PKDV, Christodoulou P, Subramanian VS (1999) Feasibility studies on the production of electro-discharge machining electrodes with rapid prototyping and electroforming process. J Mater Process Technol 89-90: 231-237.

80. Noguchi H, Nakagawa T (1999) Manufacturing of high-precision forming tool transferred from laser stereo lithography models by powder casting method. Computers in Industry 39: 55-60.

81. Allan EW, Chris EB, Graham RB (2001) Electroforming of rapid prototyping mandrels for electro-discharge machining electrodes. J Mater Process Technol 110: 186-196.

82. Zhao J, Li Y, Zhang J, Yu C, Zhang Y (2003) Analysis of the wear characteristics of an EDM electrode made by selective laser sintering. J Mater Process Technol 138: 475-478.

83. Dimla DE, Hopkinson N, Rothe H (2004) Investigation of complex rapid EDM electrodes for rapid tooling applications. Int J Adv Manuf Technol. 23: 249-255.

84. Jose Carvalho Ferreira, Artur S. Mateus, Nuno F. Alves (2007) 'Rapid tooling aided by reverse engineering to manufacture EDM 
electrodes', Int. Journal of Advanced Manuf. Technol. 34: 11331143.

85. John Kechagias, Vassilis Iakovakis, Manolis Katsanos, Stergios Maropoulos (2008) EDM electrode manufacture using rapid tooling: a review. J Mater Sci 43: 2522-2535.

86. Hsu, CY, Chen, DY, Lai, MY, Tzou, GJ (2008) EDM electrode manufacturing using RP combining electroless plating with electroforming', Int J Adv Manuf Technol 38: 915-924.
87. Tsai HC, Yan BH, Huang, FY (2003) EDM performance of $\mathrm{Cr} / \mathrm{Cu}$ based composite electrodes. Int J Mach Tools Manuf 43: 245-252.

88. Kadir Dursun and Can Cogun (2009) Use of wire bunch electrodes in electric discharge machining. Rapid Prototyping Journal 15/4: 291-298.

89. Shibayama T, Kunieda M (2006) Diffusion bonded EDM electrode with micro holes for jetting dielectric liquid. CIRP Annals Manufacturing Technology: 171-174. 